\title{
Clinical Hand Off (Transfer of Care): A Plea for Human Factor Engineering
}

\author{
Col Shashivadhanan \\ Senior Adviser Surgery \& Neurosurgery, Army Hospital Research \& Referral, Delhi 110010, India
}

\begin{abstract}
Hand off refers to transfer of heath care form one provider to the other. The transfer could mean transfer of information, responsibility or authority from one clinician to the other.Burton and Eaton et al have defined Hand off as verbal and written communication between health care professionals as they transition between work shifts or transfer of primary responsibility of care from one person to other. In the present era of exploding technologyand super specialization, it is not only inescapable but also necessary to give the patient the best in health care that is available. This involves frequent transfers. These transfers can involve hand off within a health care set up from one clinician to the other, during duty shift changes ortransfers from one institute to the other. Communication is particularly important but vulnerable to error during times of transition or a "hand-off" from one healthcare professional to another.Several studies conducted so far have highlighted failure of communication between health care personnel as a major threat to patient safety. These failures also account for over $60 \%$ of root causes of sentinel events as reported to the Joint Commission on Accreditation of Healthcare Organizations. The unaware patient is exposed to a complex health care environment which has been undergoing a dynamic change. Adding on to this are variations in clinical practice in various departments within the same health care set up. To provide seamless and uninterrupted health care there should be continuity of information, management and also relations. Previous studies have aimed to define the characteristics of a "hand-off"' in a variety of settings and contexts such as nursing shift report, ambulance to hospital transfer, and emergency medicine shift changes. Despite all efforts there is a lot that needs to be achieved. To overcome the hand off barrier certain key strategies have been proposed.They include incorporation, standardization and universal implementation of hand off tools, holding frequent education sessions for health care providers as well other stake holders so that hand off becomes smooth and error free. Computer technology can be utilized to incorporate online forms,check lists. It can also provide a structure to guide health care providers when it comes to sharing relevant and critical information.
\end{abstract}

Keywords: Hand Off

\section{Introduction}

Health care delivery in the developed and developing countries is undergoing a paradigm shift. The concept of the good old family doctor who was the"be all and end all", has taken a severe beating. The level of comfort, care and relationship shared between the doctor and his patient have been slowly been fragmented and transformed into an era of modern medicine where patient and his family can no longer be treated by a single family physician. This has been coupled with a seady rise in litigation against the healt care providers.The growing challenge of understanding and treating a disease requires an equally potent technology and expertise which the health care providers needs to possess. Patients are increasingly seen by an array of providers in a wide variety of organisations and places, raising concerns about fragmentation of care. Policy reports and charters worldwide urge a concerted effort to enhance continuity. $[1,2$ ].

This transfer of patient care from one individual to another require precise and unambiguous communication.Failurein communication can seriously jeopardize patients safety[ $3,4,5,6]$

\section{Magnitude of the problem}

Sentinel and event statistics report of Joint Commission on Accreditation of Health Care Organizations have come up with the fact that communication failure is the root cause of sentinel events in $60 \%$ of cases [7 ].Investigations into the nature of human errors in hospital are rare. Hence there is a paucity of literature in this regard. The reason can be partly attributed to the fear of legal liability.Observations during routine daily activities in the intensive care unit (ICU) demonstrated that mistakes do occur, sometimes with severe consequences. [ 8,9 ]. Reducing incidence of these events will require identification of their causes and developing methods to prevent errors or reduce their effect.

Donchin et al conducted a prospective study in the Intensive care Unit(ICU) of a tertiary care hospital and reported that 178 activities were carried out on each ICU patient every day.Out of these $0.95 \%$ were erroneous. Twenty-nine percent of the errors were graded as severe or potentially detrimental to the patients if not discovered in time. Compared with nurses, physicians had a much higher rate of error. While nurses are mainly involved in routine and repetitive activities, physicians' activities comprise a much higher percentage of reactive and initiated interventions. Initiated and reactive activities are, by default, less predictable and more susceptible to stress, and hence they also have increased probability for error. Also, each physician is expected to keep track of a larger number of patients in the ICU as compared with nurses [10].

Jeannie and colleagues identified three types of continuity in every discipline of health care - informational, management, and relational. The importance attached to each type differs according to the providers and the context of care, and each can be viewed from either a person focused or disease focused perspective [11]. 


\section{International Journal of Science and Research (IJSR) \\ ISSN (Online): 2319-7064}

Index Copernicus Value (2015): 78.96 | Impact Factor (2015): 6.391

\section{Importance of Hand Off in patient transference}

Handoffs are referred to as a transfer of care involving a transfer of information, responsibility, and authority between clinicians [12, 13]. Effective handoffs are instrumental for successful patient care management activities such as communication $[14,15]$ Coordination[16] and sense making, thus contributing to better quality of care.[17,18]

\section{Factors Affecting Hand off}

The quality of handoffs, however, is adversely affected by several factors: The important ones include

1) Lack of standardized handoff tools [19]

2) Iinformation omissions and inaccuracies [20]

3) Communication breakdowns related to language, social, and skill issues $[21,22,23]$

4) Lack of training [24]

5) Contextual constraints [25]

6) These factors are usually exacerbated in academic settings by restrictions on resident workhours that increase the frequency of transitions [26,27].

Communication is particularly important but vulnerable to error during times of transition or a "hand-off' from one healthcare professional to another. Previous studies have aimed to define the characteristics of a "hand-off" in a variety of settings and contexts such as nursing shift report, ambulance to hospital transfer, and emergency medicine shift changes[28,29,30,31]Another time of transition that requires effective communication is the transfer of care for hospitalized patients from one physician to another during shift changes. This transfer or "sign-out" can refer to either the verbal or written communication of patient information which is designed to familiarize oncoming or covering physicians with patients for whom they will be responsible.

Effective verbal communication is still important to ensure proper transmission of information. For instance, the replacement of a telephone call for reporting critical laboratory values in an emergency room with an electronic results reporting system with no verbal communication resulted in $45 \%$ of emergency laboratory results going unchecked.[32]

\section{Remedial Measures}

To address these challenges, the Joint Commission has suggested the adoption of strategies for standardized and systematic communication $[33,34]$.

These standardization efforts have resulted in the widespread development and implementation of handoff strategies, with varying degrees of success [35].

The unaware patient is exposed to a complex health care environment which has been undergoing a dynamic change. Adding on to this are variations in clinical practice in various departments within the same health care set up. Regardless of the early successes in handoff implementations[ 36], broader issues of handoff tool sustainability and consistency, and its ability to maintain seamless transitions across providers and settings, still persist. The standardized information transfer and communication requires further refining and scrutiny.

It is also important to recognize that a technological solution cannot alone substitute for a successful "communication act' [37].The use of more structured verbal communication such as "read-backs" during telephone calls of critical laboratory results has been shown to decrease errors in telephone laboratory reporting[38].Lack of or ineffective verbal communication at the time of hand-offs has emerged as a common theme surrounding adverse event and near miss situations in nursing [39].These findings, suggest that proper verbal communication during sign-out is important for safe patient care. For this reason, standard educational programs should be considered to train residents to communicate effectively at the time of hand-offs. The richness and effectiveness of faceto-face communication in the context of hand-offs in medicine and other industries should be emphasized [40]. The need for complete but relevant sign-outs reflects the delicate balance between delivering too much or too little information, a sentiment also expressed by nurses for their verbal communication during "report", or shift change [41].Achievement of this skillful verbal communication during sign-out may require adoption of standard language [42].One possible tool to facilitate this is the Situational Debriefing Model, otherwise known as "SBAR"' (situation, background, assessment, and recommendation). This model, having its origin in the Navy, can be used in health care to improve communication of critical information in a timely and orderly fashion[43]. The use of critical incident analysis and peer evaluations, as described in one study, is a potential way for teaching and improving resident sign-out [44].

To overcome these handoff barriers, some key strategies have been proposed such as (a) the incorporation of standardization methods for instance, with the use of templates, heuristics and communication mnemonics (e.gs. including SBAR (Situation, Background, Assessment and Recommendation)(b) the incorporation of education sessions to better train care providers perform effective handoffs, for instance, with the use of simulated clinical exercises, and finally (c) the incorporation of tools such as online forms, checklists and other computerized technologies that can provide a structure to guide healthcare providers to share relevant and critical information [46].

\section{Conclusion}

Great efforts have been invested in the industrial sector intheanalysisofjobrequirementsandthedesignofworkplaces, equipment, and the physical environment for the benefit of workers.Inairtrafficcontrol,forinstance, humanfactorshave been studied extensively[47]In contrast,not much attention has been given to human factor considerations in the hospital setting. As malpractice premiums have increased, hospitals tend to spend more time preparing themselves against liability claims rather than actively trying to avoid errors. We have reached a state where it would be wiser to identify the weakest link in health care and take remedial measures to prevent or reduce them. A significant number of 


\section{International Journal of Science and Research (IJSR) \\ ISSN (Online): 2319-7064}

Index Copernicus Value (2015): 78.96 | Impact Factor (2015): 6.391

dangerous human errors occur in the ICU of any Hospital. Many of these errors

Could be attributed to problems of communication between the physicians and nurses. Applying human factor engineering concepts to the study of the weak points of a specific health care set up may help to reduce the number of errors. We must realize that no two human being $\mathrm{s}$ are identical, therefore there is bound to be some mismatch in transference of health information .Human error factor cannot be totally eliminated.Errors should not be considered as an incurable disease, but rather as preventable phenomenon[10 ].A rule of thumb cannot be applied across the board as there are various factors that need to be considered.The health care providersof each set up mustsit and device an own protocol suiting their clientele. The remedial measures suggested so far provide the basic infrastructural guidelines upon which standard protocols can be built. The earlier done the better

\section{References}

[1] World Health Organization. The Ljubljana charter on reforming health care, 1996.www.euro.who.int/AboutWHO/Policy/20010927 $\underline{5}$ (accessed 7 May 2003).

[2] Fulop N, Allen P. National listening exercise: report of the findings. London: NHS Service Delivery and Organisation National Research and Development Programme, 2000.

[3] Wilson RM, Runciman WB, Gibberd RW, et al. The quality in Australian health care study. Med J Aust 1995;63:458-71.

[4] Lingard L, Espin S, Whyte S, et al. Communication failures in the operating room: an observational classification of recurrent types and effects. QualSaf Health Care 2004;13:330-4.

[5] Sutcliffe KM, Lewton E, Rosenthal MM. Communication failures: an insidious contributor to medical mishaps. Acad Med 2004;79:186-94.

[6] Department of Health. Organisation with a memory, Report of an Expert Group on Learning from Adverse Events in the NHS. London: HMSO, 2000

[7] Joint Commission on Accreditation of Healthcare Organizations. Sentinel event statistics. Available at: http://www.jcaho.org/

accredited+organizations/sentinel+event/sentinel+event +statistics.htm

[8] Brennan TA, Leape LL, Laird NM, et al .Incidence of adverse events and negligence in hospitalized patients. N Engl J Med 1991;324:370-6.

[9] Abramson NS, Wald KS, Grenvik ANA, et al. Adverse occurrences in intensive care units. JAMA 1980;244:1582-4.

[10] Y Donchin, D Gopher, M Olin, Y Badihi, M Biesky, C L Sprung, R Pizov, S Cotev. A look into the nature and causes of human errors in the intensive care unit.QualSaf Health Care 2003;12:143-148.

[11] Jeannie L Haggerty, Robert J Reid, George K Freeman, Barbara H Starfield, Carol E Adair, Rachael McKendry, Continuity of care:A multidisciplinary review. BMJ,2003 Nov 22; 327(7425): 1219-1221.
[12] Arora V, Johnson J, Meltzer D, et al. A theoretical framework and competency-based approach to improving handoffs.Qual Safety Health Care 2008;17:11-14 [PubMed]

[13] Strople B, Ottani P. Can technology improve intershift report? What the research reveals. J Prof Nurs 2006;22:197-204 [PubMed]

[14] Apker J, Mallak L, Gibson S. Communicating in the 'gray zone': perceptions about emergency physician hospitalist handoffs and patient safety. AcadEmerg Medicine 2007;14:884-94 [PubMed]

[15]Flanagan ME, Patterson ES, Frankel RM, et al. Evaluation of a physician informatics tool to improve patient handoffs. J Am Med Inform Assoc 2009;16:509-15 [Mㅡ free article] [PubMed]

[16] Patterson ES, Roth EM, Woods DD, et al. Handoff strategies in settings with consequences for failure: lessons for health care operations. Int $\mathrm{J}$ Qual Health Care 2004;16:125-32 [PubMed]

[17] Gandhi TK. Fumbled handoffs: one dropped ball after another. Ann Internal Med 2005;142:352-58 [PubMed]

[18] IOM Crossing the quality chasm : a new health system for the 21st century. Washington, DC: National Academy Press, 2000

[19] Vidyarthi AR, Arora V, Schnipper JL, et al. Managing discontinuity in academic medical centers: strategies for a safe and effective resident sign-out. J Hospital Med 2006;1:257-66 [ㅁubMed]

[20]Cheung DS, Kelly JJ, Beach C, et al. Improving handoffs in the emergency department. Ann Emerg Med 2009;55:171-80 [ㄹuMed]

[21] Berkenstadt H, Haviv Y, Tuval A, et al. Improving handoff communications in critical care. Chest 2008;134:158-62 [PubMed]

[22] Lingard L, Espin S, Whyte S, et al. Communication failures in the operating room: an observational classification of recurrent types and effects. Qual Safety Health Care 2004;13:330-34 [PMC free article] [PubMed]

[23] Solet DJ, Norvell JM, Rutan GH, et al. Lost in translation: challenges and opportunities in physicianto-physician communication during patient handoffs. Acad Med 2005;80:1094-99 [PubMed]

[24] Horwitz L, Moin T, Green M. Development and implementation of an oral sign-out skills curriculum. J Gen Intern Med 2007;22:1470-74 [PMC free article][PubMed]

[25] Laxmisan A, Hakimzada F, Sayan OR, et al. The multitasking clinician: decision-making and cognitive demand during and after team handoffs in emergency care. Int J Med Inform 2007;76:801-11 [PubMed]

[26] Accreditation Council for Graduate Medical Education Web site. Report of the work group on resident duty hours and the learning environment. June 11, 2002. In: The ACGME's approach to limit resident duty hours 12 months after implementation: a summary of achievements, 2004 http://www.acgme.org/acWebsite/dutyHours/dh_achiev eSum04-05.pdf.

[27] Arora J, Lovinger D, Humphrey HJ, et al. Communication failures in patient sign-out and suggestions for improvement: a critical incident 


\section{International Journal of Science and Research (IJSR) \\ ISSN (Online): 2319-7064 \\ Index Copernicus Value (2015): 78.96 | Impact Factor (2015): 6.391}

analysis. QualSaf Health Care 2005;14:401-07 [프 free article] [PubMed]

[28] Lally S.An investigation into the functions of nurses' communication at the inter-shift handover. J NursManag 1999;7:29-36.

[29] Sherlock C. The patient handover: a study of form, function and efficiency. Nursing Standard 1995;52:336.

[30] Beach C, Croskerry P, Shapiro M. Center for Safety in Emergency Care. Profiles in patient safety: emergency care transitions, AcadEmerg Med 2003;10:364-7.

[31] Thakore S, Morrison W.A survey of perceived quality of patient handover by ambulance staff in the resuscitation room.Emerg Med J 2001;18:293-6.

[32] Kilpatrick ES, Holding S. Use of computer terminals on wards to access emergency test results: a retrospective audit. BMJ 2001;322:1101-3.

[33] Joint Commission FAQs for the 2008 National Patient Safety Goals (updated 3/08), 2008.

[34] Eldridge N, Revere A. Joint Commission on Accreditation of Healthcare Organizations (JCAHO) National Patient Safety Goals for 2005. Topics in Patient Safety 2005;5:1-2.

[35] Riesenberg LA, Leitzsch J, Little BW. Systematic review of handoff mnemonics literature.Am J Med Qual 2009;24:196-204 [PubMed]

[36] Rabinovitch DL, Hamill M, Zanchetta C, et al. Nurse practitioner-based sign-out system to facilitate patient communication on a neurosurgical service: a pilot study with recommendations. J NeurosciNurs 2009;41:329-35 [PubMed]

[37] Ash JS, Berg M, Coiera E. Some unintended consequences of information technology in health care: the nature of patient care information systemrelated errors. J Am Med Inform Assoc 2004;11:121-4.

[38] Barenfanger J, Sautter RL, Lang DL, et al. Improving patient safety by repeating (read-back) telephone reports of critical information. Am J ClinPathol 2004;121:8013.

[39] Ebright PR, Urden L, Patterson E, et al. Themes surrounding novice nurse nearmiss and adverse-event situations. J Nurs Admin 2004;34:531-8.

[40] Patterson ES, Roth EM, Woods DD, et al. Handoff strategies in settings with high consequences for failure: lessons for health care operations. Int J Qual Health Care 2004;16:125-32. 28 Cockburn A. Agile Software Development. Boston: Addison-Wesley, 2002

[41] Kerr MP.A qualitative study of shift handover practice and function from a socio-technical perspective. $\mathrm{J}$ AdvNurs 2002;37:125-34.

[42] Leonard M, Graham S, Bonacum D. The human factor: the critical importance of effective teamwork and communication in providing safe care. QualSaf Health Care 2004;13(Suppl I):i85-90.

[43] British Medical Association. Safe handover: safe patients. Guidance on clinical handover for clinicians and managers. London: BMA, Available at http://www.bma.org.uk/ap.nsf/Content/Handover/\$file/ Handover.pdf (accessed 22 December 2004).

[44] V Arora, J Johnson, D Lovinger, H J Humphrey, D O Meltzer, Communication failures in patient sign-out and suggestions for improvement: a critical incident analysis. QualSaf Health Care 2005; 14:401-407.
[45] Joanna Abraham, Vickie Nguyen, Khalid F. Almoosa, Bela Patel, Vimla L. Patel. Falling through the Cracks: Information Breakdowns in Critical Care Handoff Communication,AMIA AnnuSymp Proc.2011; 2011: 28-37.

[46]Lenorovitz DR, Phillips MD: Human factors requirements engineering for air traffic control system. In: Salvendy G, ed. Handbook of human factors . New York: John Wiley, 1987, 1771-893. 